\title{
THE MODEL OF GAS POOL FORMATION IN FRAKULLA AREA, ALBANIA R. KOCI ${ }^{1}$, A. GJIKA ${ }^{1}$, Q. AVDULAJ', S. KOCI ${ }^{1}$
}

\section{ABSTRACT}

Frakulla diapir is one of the studied diapirs in Albania. It is located in the western part of Albania. The Serravallian to Pliocene sediments belongs to the uppermost part of the Adriatic Basin, which is included in the central Mediterranean Basins group.

Some anticline and syncline structures are indicated in the western part of Albania. These structures are placed in a linear way forming some structural ranges with SSE-NNW axis direction. Frakulla is one of these structures as a part of Vlora-Panaja-Frakkull range (Fig. 1).

Based on the surface geology, well data and the interpretation of the seismic sections results that this structure is formed as a consequence of the mud diapir growth.

This diapir is complicated with tectonic faults in both western and eastern flanks, which dip with angle 45$90^{\circ}$. The southern and northern ends of the structure are clearly seen in the seismic sections and a number of wells penetrated these ends.

We think that the Frakulla structure is a typical mud diapir surrounding in all directions by many gas sandstone beds. These sandstones are formed in a deltaic environment during the Messinian (Globorotalia conomiozea zone).

Some factors affected the quantity of hydrocarbon accumulation are discussed in this paper like: structural character of the area, pattern and complexity of faulting around and over the mud diapir, depositional environment, rate of growth of the diapir and time of uplift.

We think that the presence of gas accumulation in Frakulla area is as a consequence of a favorable interrelation of these factors.

KEY WORDS: Adriatic Basin, Albania, Frakulla diapir.

\section{INTRODUCTION}

We would like to present the Frakulla diapir as a special case where the interrelation of some factors leads to the gas pools formation.

We are based on the surface geology and to a lot of well data and seismic lines. We think it is a good example, which can help in the determination of the most successful and probable zones around such diapirs for exploration.

The identification of mud diapir based on the geological data

Frakulla region is stratigraphically represented by Neogene deposits

(Serravalian to Pleistocene included) which are placed with stratigraphic and angular unconformity in the lateral parts of the basin.

From the lithological point of view the section is represented by clay, siltstone, sandstone, and evaporates.

Clay package in the lower part of Messinian deposits belongs to a deep-sea depositional environment; while the overlaid clay-sandstone package is deposited in a shallow environment of lagoon type.

Based on the sediment thickness (Tortonian and Messinian sediment thickness is bigger) and on the small unconformity between Messinian and Pliocene deposits it is concluded that the Frakulla structure is formed after Pliocene time.

The initial differentiation of Frakulla structure is as a result of eastern tangent forces (the development of Patos-Verbasi and Kreshpani structures) which lead to the formation of Frakulla diapir itself and to the Peshtani and Semani synclines on both its flanks.

Based on the interpretation of the seismic sections (fig 2,3) and to the well data we reached to the conclusions that the mud diapir was developed in the central part of the structure. The faults on both flanks of the structure are as a result of diapir development. The dip of these faults in crease to the depth. The faults intersect

1. Oil and Gas Institute, Lagja 1 Maj, Fier, ALBANIA 


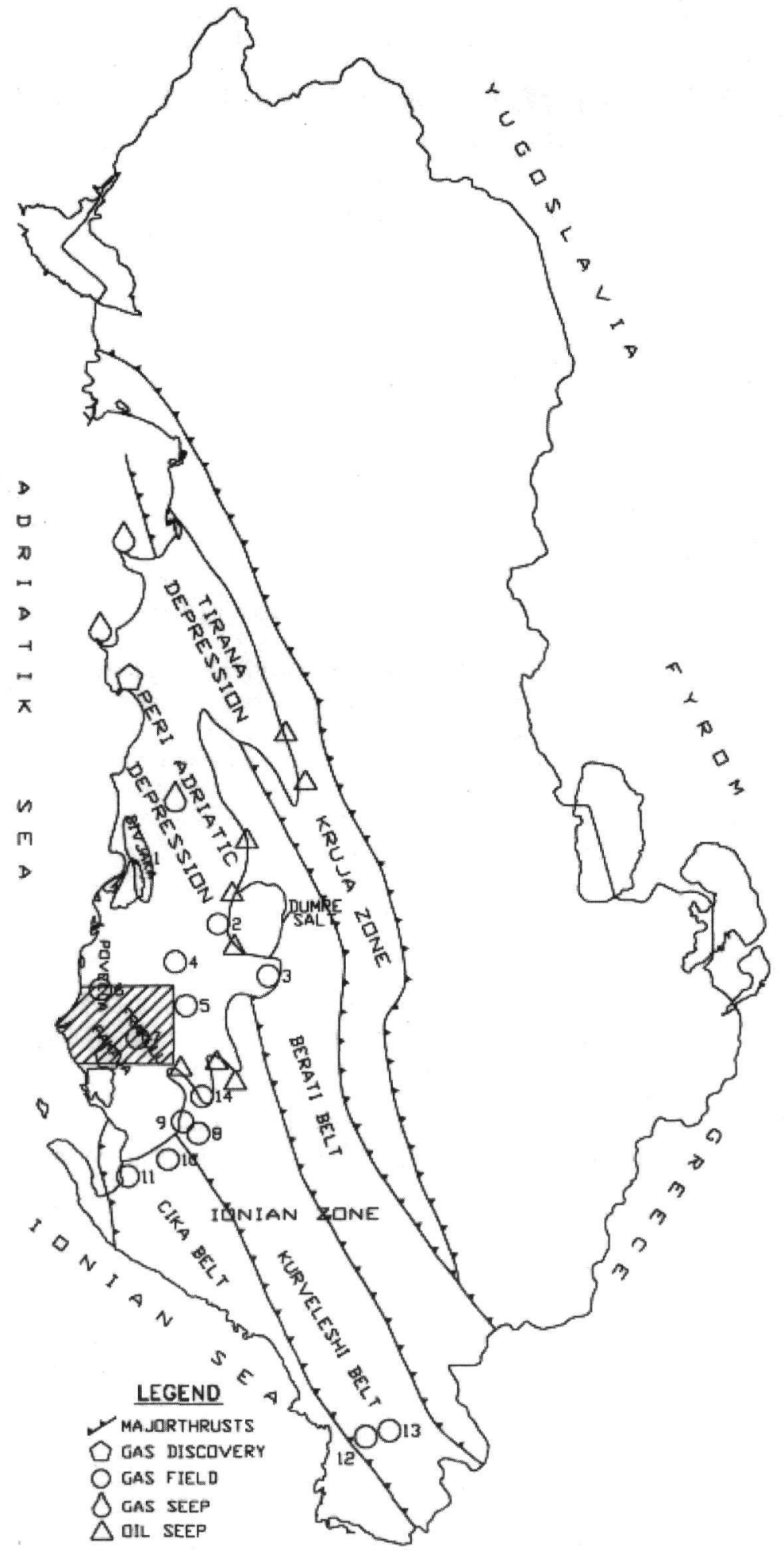

Fig1. Structural map of Albania 


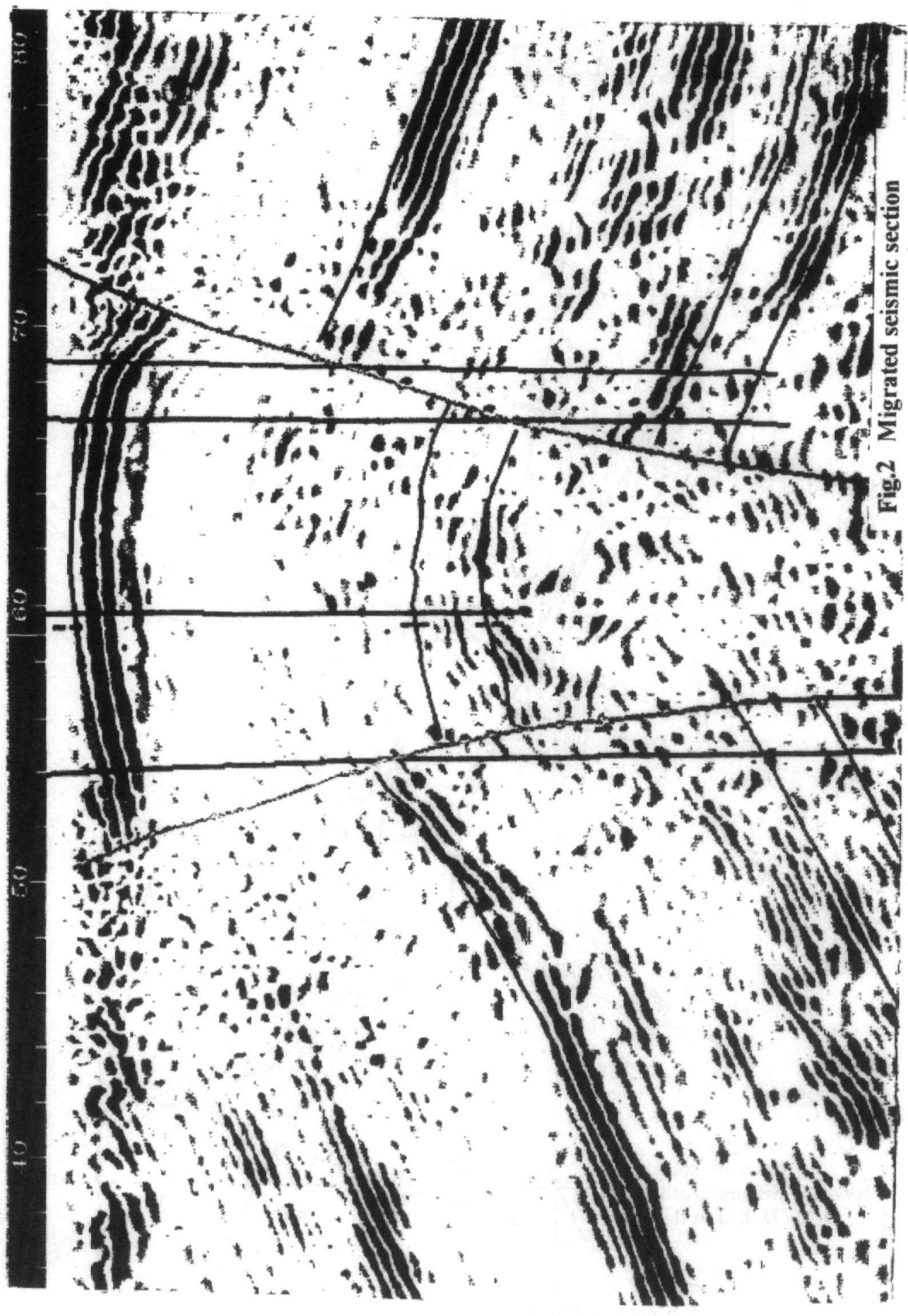




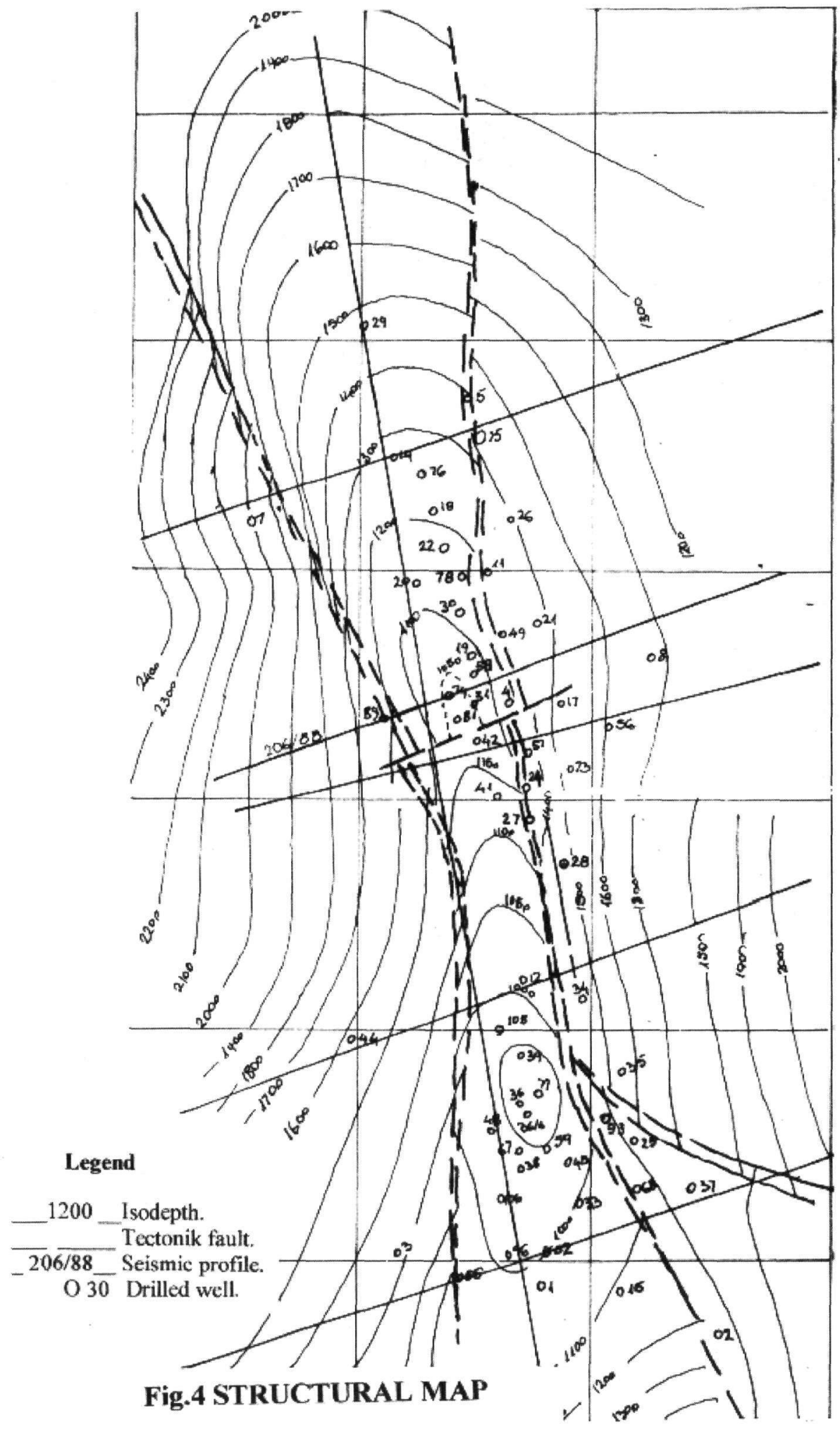




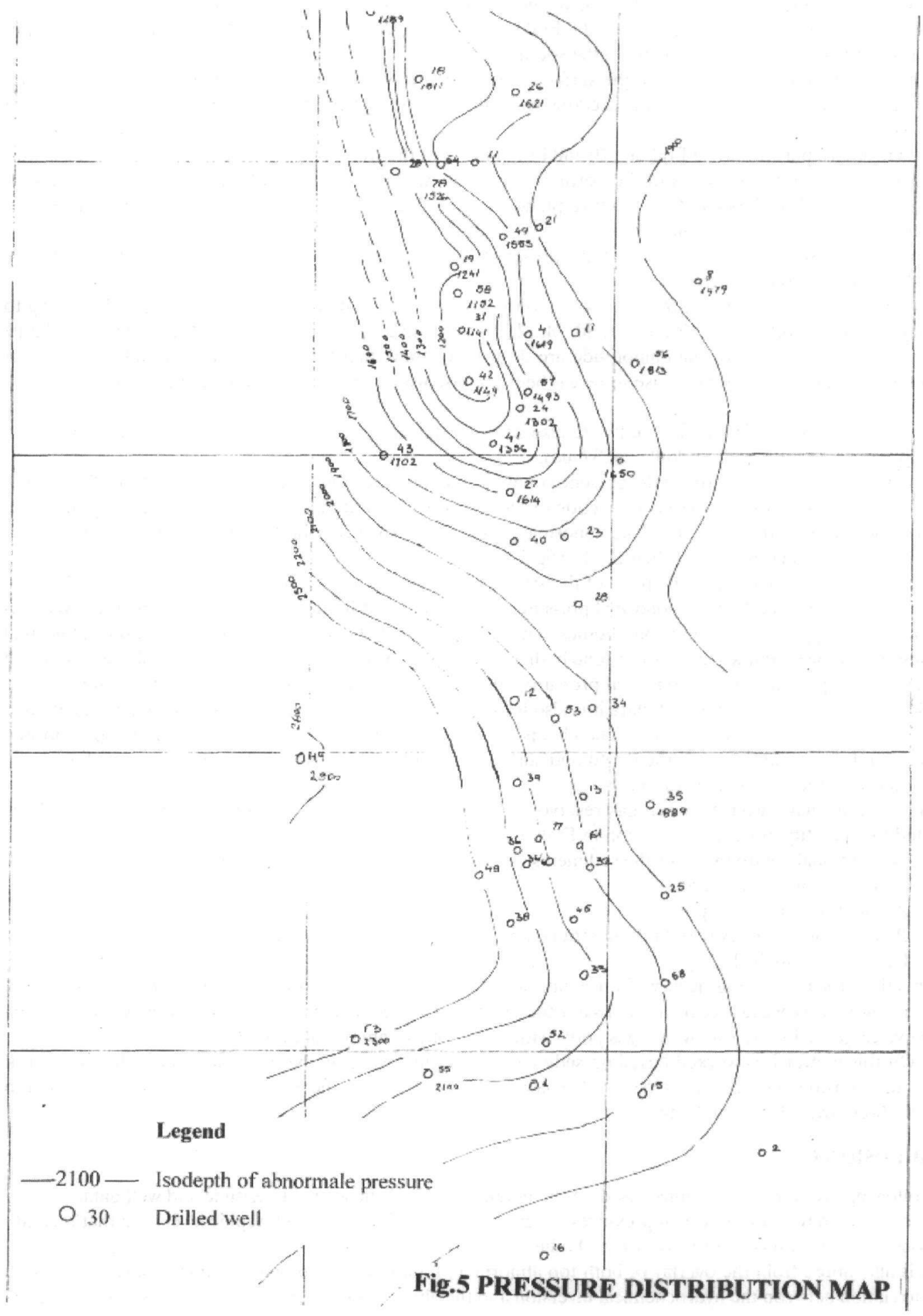


the Pliocene sediments so they are of post Pliocene in age and hence they are formed as a consequence of a post Pliocene tectonic phase.

The western fault is clearly seen on the geological map (in the surface) in the northern part of the region. It is also drown from the well data (Frakulla 89, Frakulla 7, Frakulla 43 and Frakulla 75 etc). The vertical amplitude is $400-500 \mathrm{~m}$ at the north reducing to the south (fig 2, 3).

The eastern fault does not exist to the surface. It is clearly drown from the well data (Frakulla 54, 68, 4, 11, 49, 57, 27, etc. Fig. 4) and the seismic sections changing to a flexure from the depth towards the Messinian deposits.

The northern part (between Frakulla 20 and Frakulla 74) of the structure has been shallower than the southern part. The abnormal pressures in the northern part are also encountered shallower than the southern part (fig 5). At the end of Pliocene the structure plane changed deepening the northern part of the structure in comparison with the southern one.

So, based on such tectonic style and to the presence of a totally clay section of the central part the contours of Frakulla mud diapir are drown.

The Frakulla structure going from the south to the north has not any very regular form (fig 4). Referring to the well data (Frakulla 38, 59, 109, 45, 81, 80, 74, 31, 42, etc) and to the seismic sections (fig 3, etc) some faults with east-west direction and small amplitude are drown. We think that these faults have played an important role in the gas pool formation because some gas beds are discovered in the zones between the above mentioned wells .

Other small amplitude tectonic faults are also shown in the eastern structural flank (the zone between the wells Frakulla 24, 27, 72 and Frakulla 25, 37, 68).

Many drilled wells have proved the presence of abnormal pressure in every part of the structure. The data of their correlation were used for the construction of the pressure distribution map. This map looks very similar in comparison with the structural map. The abnormal pressures are shallower in the central zone or in the uppermost part of the structure than in their flanks (fig 5).

The pressure gradient in all the parts of the structure reaches up to 1.1-1.3 atm.

It was also indicated that the abnormal pressures are encountered in the different stratigraphycal level conditioned by the presence of sandstone bodies. That means that if the section is clayey the top of abnormal pressure is shallower and when the sandstone bodies are deeper, the abnormal pressure top is also encountered deeper. So, the presence of the abnormal pressure indicates the presence or not of the sandstone bodies.

Based on the correlation of well data it is also looked that exists a relationship between the abnormal pressure and the hydrochemical inversion. The chemical mineralization is higher near the level of top abnormal pressure and decreasing towards the depth and surface. (Frakulla 4/b, 8, 10, 20, 24,). This relationship is as a consequence of their syngenetic origin.

It is also a relationship between gas reservoirs and the mud diapir. There are a lot of factors that have affected the quantity of gas accumulation in Frakulla diapir as:

-Depositional environment of the sediments

-Time of uplift of the diapir

-Amount of structural uplift

-Patterns and complexity of faulting around and over the diapir

-Dip of the flank beds

In spite of some drilling deep wells it is not achieved to discover gas pools within the zone of abnormal pressure, and this is because of the lack of sandstone bodies. This problem needs to be discussed, since in Panaja and Povelca gas fields are discovered gas pools within the zone of abnormal pressure.

On this matter it is worked based on sedimentologic analyses of the basen to determine the location of spreading sandstone bodies, in analogy to Panaja and Povelca in which the gradient of pressure is expected to fall but always over the normal one.

\section{CONCLUSIONS}

Following are some conclusions based on the detailed study of the available seismic and well data.

1. It is indicated that the abnormal pressures are encountered in different stratigraphic levels and that is conditioned by the presence of the sandstone bodies.

2. It is also noted from the overlay of both top abnormal pressure map and hydrochemical maps that exists a correlation between the hydrochemical inversion and the abnormal pressures. The top of the abnormal pres- 
sure represents also the bottom of the hydrochemical inversion. We think that this correlation exist as a consequence of the syngenetic origin both for abnormal pressure and hydrochemical inversion.

3. Gasbearing section of this gas field belongs to the upper part of Messinian deposits and its thickness is about $1500 \mathrm{~m}$.

4. The most encountered gas beds are those of lithologo-structural and tectonic types and are discovered both in the eastern part and in the top of structure.

\section{BIBLIOGRAPHY}

FILI I,KOÇI R,1988,- The exploration of new gas pools in Frakulla area.(Oil and gas Institute Achieve). FILI I,KOÇI R,1990,- A study of Panaja-Frakulla area for gas exploration. (Oil and gas Institute Achieve). FILI I,KOÇI R,1998,- A complex study of Frakulla gas field.(Oil and Gas Institute Achieve). 